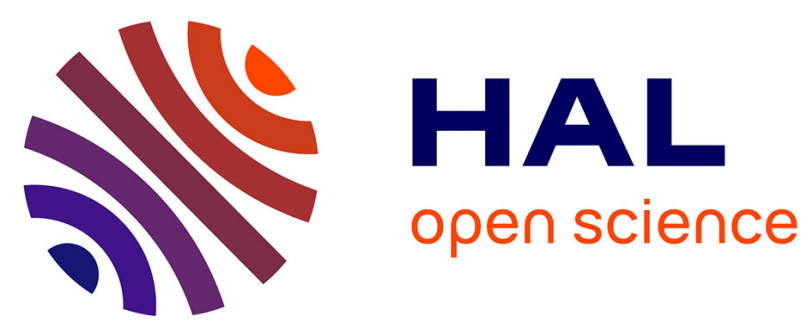

\title{
Why Did Leopards Kill Humans in Mumbai but not in Nairobi? Wildlife Management in and Around Urban National Parks
}

Frédéric Landy, Estienne Rodary, Bernard Calas

\section{- To cite this version:}

Frédéric Landy, Estienne Rodary, Bernard Calas. Why Did Leopards Kill Humans in Mumbai but not in Nairobi? Wildlife Management in and Around Urban National Parks. Frédéric Landy. From Urban National Parks to Natured Cities in the Global South: The Quest for Naturbanity, Springer Singapour, pp.157-179, 2018, 978-981-10-8461-4. 10.1007/978-981-10-8462-1_7 . hal-02111965

\author{
HAL Id: hal-02111965 \\ https://hal.science/hal-02111965
}

Submitted on 3 Feb 2020

HAL is a multi-disciplinary open access archive for the deposit and dissemination of scientific research documents, whether they are published or not. The documents may come from teaching and research institutions in France or abroad, or from public or private research centers.
L'archive ouverte pluridisciplinaire HAL, est destinée au dépôt et à la diffusion de documents scientifiques de niveau recherche, publiés ou non, émanant des établissements d'enseignement et de recherche français ou étrangers, des laboratoires publics ou privés. 


\section{Chapter 7 \\ Why Did Leopards Kill Humans in Mumbai but not in Nairobi? Wildlife Management in and Around Urban National Parks}

$6 \quad$ Frédéric Landy, Estienne Rodary and Bernard Calas

In 2004, leopards killed 19 people in Mumbai. Although fatal attacks have diminished since 2007 (Fig. 7.1), they show the scale of a problem that has received extensive local and even international media coverage. These attacks took place inside or on the edge of the Sanjay Gandhi National Park (SGNP), mainly in areas occupied by slums. They raised questions about the wisdom of siting a national park in a megacity of some 20 million inhabitants, the excessive density of the leopard population, and a way of managing space which in 1995 has seen more than 500,000 slum dwellers living in the park.

That at least is the view one might take on consideration of the Mumbai case alone. However, a comparative approach prompts a different way of thinking about things. In Nairobi, a city of 4 million people, the national park of the same name also borders slum areas and is home to a fairly dense population of leopards (as well as lions, hyenas and hippopotamuses), which represents a potential danger. Yet no wild animals have killed human beings in the park in living memory, other than a few incautious tourists who have left their cars to take close-up photographs of lion cubs jealously protected by their mothers.

How can this difference between Mumbai and Nairobi be explained? What is it that differs in the "humanimal" (Estebanez et al. 2013) relationship that sometimes makes the encounter between man and cat more dangerous for the man (and for the animal) in Mumbai than it is in the Kenyan capital? An initial hypothesis might be that a different way of managing the park, better coordinated with the management of the city, explains the absence of human victims in Nairobi. Perhaps the actors in

F. Landy (ه)

University of Paris-Nanterre, Nanterre, France

e-mail: frederic.landy@ifpindia.org

E. Rodary

French Research Institute for Development, Nouméa, New Caledonia

B. Calas

Department of Geography, University of Bordeaux-Montaigne, Pessac, France

(C) Springer Nature Singapore Pte Ltd. 2018

F. Landy (ed.), From Urban National Parks to Natured Cities in the Global South,

https://doi.org/10.1007/978-981-10-8462-1_7 
Fig. 7.1 Fatal leopard attacks in or around the park 1987-2015. Source SGNP

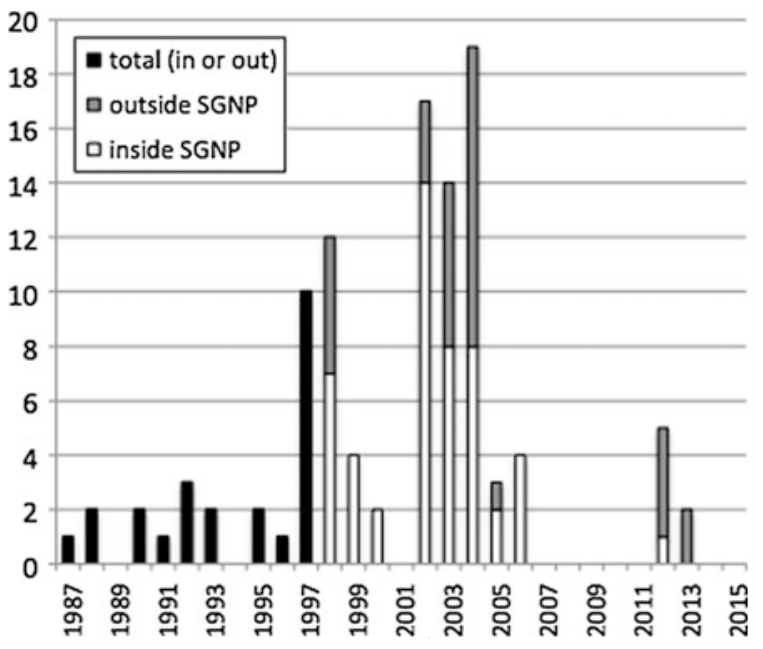

the two spheres coordinate their efforts so that wild animals can be more effectively tracked in the city. And perhaps in Mumbai, by contrast, it is because the park and the city glare at each other, so to speak, across a barrier of mutual mistrust that the management of the leopard problem leads to such bad results. However, as we will see, this hypothesis proves to be largely erroneous. Sociocultural factors such as the representations of nature, or social disparities, which generate different vulnerabilities, also need to be considered. The management of wildlife and, more broadly, the way people live with it, should be seen not as neutral techniques or practices, but as signs of an institutional machinery and-beyond this - of an ontology of nature or at least a paradigm of protection. This leads us to a second hypothesis: much more than a simple question of the material management of wandering wildlife, there are more fundamental differences in the "ideological distances" between men and animals that may explain the contrast between the two cases studied.

\subsection{Wildlife Conflicts: Situation Report}

Mumbai is considered to be the world's most densely populated city. In terms of human population, this title is disputable, given that the estimates vary depending on the surface area considered. But in terms of the leopard population, there is no dispute. A count made early in 2015 recorded 35 leopards living in or around SGNP, making a density of 22 per $100 \mathrm{~km}^{2}$, or less than $5 \mathrm{~km}^{2}$ per leopard. ${ }^{1}$ The

\footnotetext{
${ }^{1}$ Around the world, leopard densities in rainforests have been estimated to not exceed 1 per $10 \mathrm{~km}^{2}$ (Bailey 1993).
} 
attacks took place almost equally inside and outside the park (Fig. 7.1). The most recent deaths, in 2013, happened on the outskirts: a little girl urinating alongside her grandmother, after dark near her house; and a boy coming back in a group from school. The attacks thus resemble the spatial marker of a "buffer zone", an interface between the city and the park, extending in places more than $3 \mathrm{~km}$ beyond the external boundaries of SGNP (yellow squares on the map of Mumbai, see cartographic insert). At least five leopards have apparently established their territory outside the park, in Aarey Colony, an area on the outskirts of the park, situated right in the heart of Mumbai but possessing "rural" characteristics", such as dairy cattle, forest and erop villages...

Human beings are far from the only victims. On the one hand, some leopards are killed (an average of two per year), sometimes in reprisal for attacks, usually hit by vehicles (section $\mathrm{K}$ on the map following the introduction of this beok). In addition, the Adivasis, "indigenous" populations of Mumbai-who live partly in the park, regularly lose goats (sometimes raised in the park despite prohibition of the activity) or dogs which, although semi-feral, are used as an early-warning system. A CCTV video popular on the Internet shows a leopard going into the entrance hall of a building in the Mulund suburb and coming out with a dog in its jaws. ${ }^{2}$ So Mumbai's leopards are particularly intrusive, which prompts widespread fear of the animal, amounting at times to an urban psychosis.

Paradoxically, this psychosis affects all social groups (except to some extent the Adivasis, who are used to the presence of the animal), from those least exposed to risk to the most vulnerable: car-owning inhabitants of well-off households, with windows and doors in their houses, are much more strident in the media and social networks than slum-dwellers, who are actually the only victims, ${ }^{3}$ but lack the means to publicise and express their concerns. What is often called bourgeois environmentalism (Baviskar 2002) has its limits, and there are plenty of people who are "non-environmentalist bourgeois" when it comes to leopards (Landy 2017).

The situation is compared with that in Nairobi, where leopards are rarely seen in the city, although one has perhaps established its territory in the Ngong Road Forest. Here, the cat, which has a maximum density in the park of around one individual per $6 \mathrm{~km}^{2}$, kills "only" other animals: domestic animals (e.g. dogs, cats, etc.), and above all livestock belonging to the Maasai who live in the south of the park (164 pastoralists were compensated in 2012 for attacks by lions, leopards or hyenas, more than $40 \mathrm{~km}$ away from the national park, see Fig. 7.2).

A leopard that manages to enter a compound may kill all the goats and sheep inside it. So it is not that there are fewer conflicts in Nairobi than in Mumbai, it is their nature that is different. Local people sometimes call the Kenya Wildlife Service (KWS) because they have seen a carnivore in their garden, but the primary

${ }^{2}$ https://www.youtube.com/watch?v=75Yq0rOIsMY. Accessed on January 7, 2016.

${ }^{3}$ Though a lawyer from Mulund was killed in 2004, the only victim from the well-off social classes. He was in the habit of climbing into the park every morning before dawn... (Interview with members of the victim's family, January 2014). 


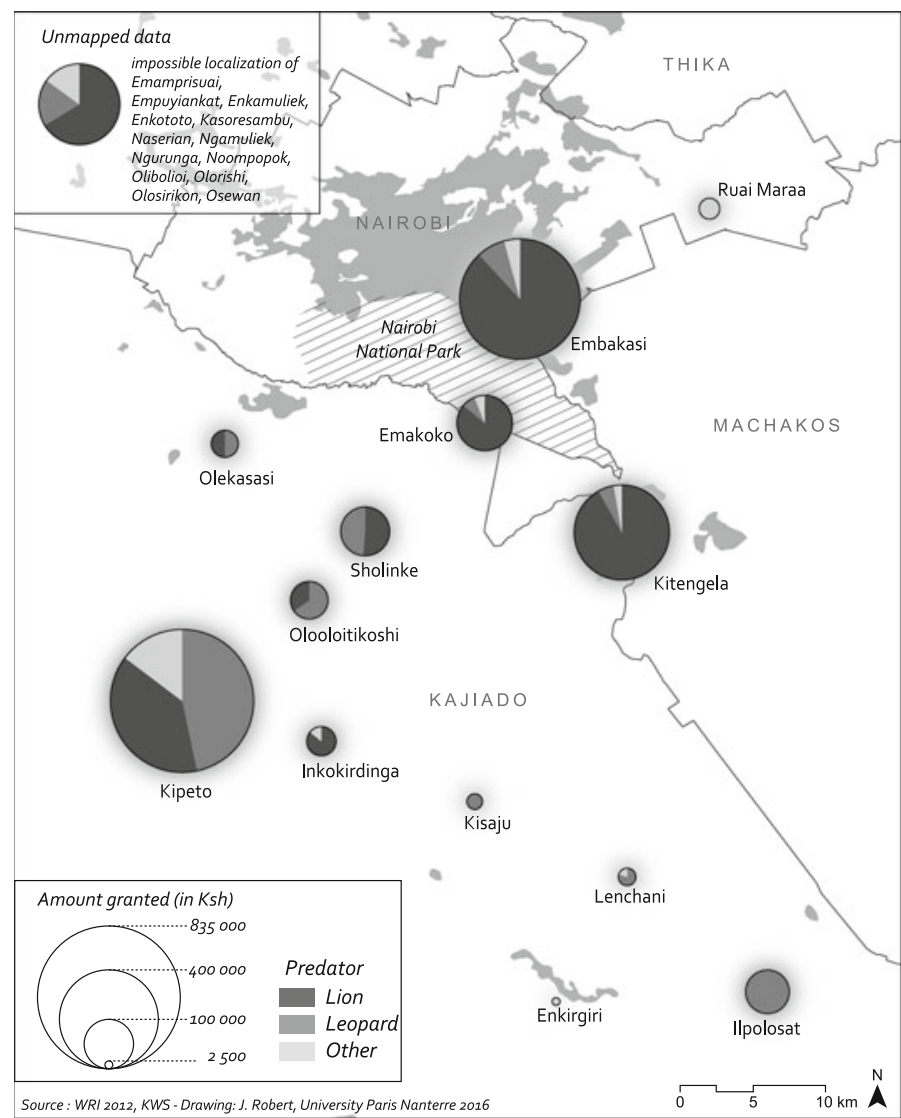

Fig. 7.2 Compensations ("consolations") granted by Kenya Wildlife Service to herders in 2012

victims of leopards or lions are livestock. That is why, despite the legal protection the big cats enjoy, the pastoralists often try to kill them in reprisal, which relocates and "humanises" the conflict.

In the city, the KWS intervenes in the whole conurbation, not only the low-density areas (e.g., villas with gardens, parks around institutions, etc.), which are the richest areas situated in the west of the city (Karen and Langata). For example, the largely abandoned industrial mining sites in the north-east of the park, where ponds can form during the rainy season, sometimes provide a habitat for hippopotamuses. And in the Kibera slum in the northern part of the park, which is too dense for many carnivores to wander, there is talk of warthogs and even hyenas digging up and eating corpses in the cemeteries.

It is time to explain why Nairobi's leopards, dangerous as these animals are to humans, are not deadly, unlike those of Mumbai. The hypotheses can be grouped 
into three broad categories: the first is ecosystem organisation, the second involves methods of managing the problem, and the third relates to sociocultural factors.

\subsection{Dogs and "Naturban" Ecosystems}

Another, highly contingent factor that lies outside these categories is chance. Given the statistical rarity of accidents, it cannot be ruled out. "We have been staying here for over 20 years and spot leopards at least three or four times a month, but to date no humans have been attacked", reported a woman from a slum in Mulund, a district of Mumbai, after the death of a little girl in $2012 .{ }^{4}$ In this respect, wildlife-related accidents are entirely specific, given that, beyond structural determinants, they are always attacks by an individual. An animal suffering particular stress is very likely to show unusual behaviour. In the Indian countryside, villages may want a specifically dangerous elephant to be culled without necessarily wishing to see the species eradicated from their area (Sekar 2013). However, chance has to be ruled out as the only explanation, since the differences in mortality between the two cities are too large to be ascribed solely to (bad) luck. Beyond this, there is the question of the agency of the animals themselves, an issue recently rediscovered by certain authors (Midgley 1979; Haraway 2008), including geographers who - accustomed to considering environmental factors - had until recently neglected the animal dimension (Wolch and Emel 1998; Blanc and Cohen 2002; Buller 2013, 2014, 2015).

The possible role of taxonomy as a factor also does not seem to offer an adequate explanation. It is true that the Indian leopard (Panthera pardus fusca) differs from the African subspecies (Panthera pardus pardus). But the fact that fatal leopard attacks have almost ceased in Mumbai since 2007 obliges us to look elsewhere. Two explanations seem much more fundamental: predation by leopards on populations of domestic dogs, and the landscape configurations of the interfaces between park and city.

The leopard is an opportunistic predator, though its preference is for medium-sized ungulates. However, there is little documentation on the cat's real specialisations in terms of prey species (Hayward et al. 2006). A recent study on all the world's leopard subpopulations shows that the shortage of total prey biomass has a direct impact on livestock predation (e.g., cattle, sheep and goats). This impact is apparent regardless of the variations in body weight, spatial range and density of the different leopard populations. The authors therefore consider that the level of available wild prey biomass per square kilometre is a good predictor of conflicts between cat and human (Khorozyan et al. 2015).

${ }^{4}$ Ranjeet Jadhav, "Leopard devours 6-yr-old in Mulund", Mid-Day, July 17, 2012, http://www. mid-day.com/articles/leopard-devours-6-yr-old-in-mulund/172727. Accessed on June 7, 2016. 
A study conducted in India's rural areas specifies the contribution of domestic animals to the leopard diet. Undertaken in Maharashtra, it shows that domestic animals represent $87 \%$ of the cat's diet, with dogs alone accounting for $39 \%$ of prey. Given the high density of goats and sheep in the countryside, dogs (together with cats) are overrepresented in the predator's diet (Athreya et al. 2014). This suggests a relationship between leopard and human that entails not a strategy of direct predation, but opportunism in a context of high predatory specialisation on domestic dogs. According to Butler et al. (2013), dog predation by large carnivores is low and infrequent around the world, but India's rural areas constitute an exception "where dogs clearly form a significant part of their diet, probably due to high dog densities and the relative scarcity of natural prey" (p. 135). This observation can be extended to urban India and in particular to Mumbai, where specialisation on dogs can once again be explained by the relatively low level of ungulate populations in SGNP (Edgaonkar and Chellam 1998; Tiwari 2008). The high density of dogs in Mumbai can cause declines in natural prey species for leopards (which in return leads to more predation on dogs). A study on the park has shown that wild animals account for 57\% of leopard prey, as compared with $43 \%$ for domestic animals, including $24 \%$ for dogs alone (Surve 2015). Other, older studies gave an even higher percentage for dogs (47\%, according to Tiwari 2009).

The situation is quite different in Nairobi, where mammal biomass and biological diversity are extremely high, in particular medium-sized mammals, both domestic (sheep...) and wild (impalas...), which constitute the preferred target for leopards (Foster and Coe 1968). This diversity has been on a downward trend for a century, but not to a significant degree (Western et al. 2009; Ogutu et al. 2013; Toth et al. 2014). Moreover, dogs are much less popular in Nairobi than in Mumbai, mainly for cultural reasons, but also because within the Indian metropolis and inside SGNP itself, the large number of slums, a habitat that offers little protection, encourages the use of dogs with varying degrees of domestication.

It is therefore very clearly the availability of prey that explains high dog predation by leopards in Mumbai and low levels in Nairobi. Human attacks in the Indian city would thus simply seem to be opportunities linked with this specialisation. Human beings are too big to constitute a preferred target for leopards, which will preferentially attack children or seated adults. The previously cited attack on a lawyer from Mulund in 2004 could only take place in steep terrain where the animal was able to spring on its victim as he was climbing among rocks.

However, these opportunities are also explained by landscape configurations. Here, two factors need to be taken into account: the dynamics of expansion in leopard populations, and their spatial hunting strategies. With regard to the dynamics of expansion, leopards are known to be solitary and territorial animals. Territories of a male and a female can overlap, but when young animals reach maturity they disperse until they find an area that is not already occupied by another individual of the same sex. Provided that prey is sufficiently abundant, these dynamics lead to a significant spatial expansion of the population. In the Mumbai case, the park - which is thought to be entirely occupied by the cat's territories-is surrounded by densely populated urban areas. The only area where the landscape 
connects to other wooded areas is located north of the protected zone, but is nevertheless crossed by an extremely busy road especially at night which is also the time when leopards use the human-used landscapes. By contrast, the interfaces between the park and the city are quite permeable: the boundary is only partially maintained by a wall, sometimes combined with barbed wire-and this often contains breaches through which animals and human beings can pass. In Nairobi, on the other hand, there is a contrast in the park boundary between its southern part, which is open to the $2500 \mathrm{~km}^{2}$ of the Kitengela migratory corridor (Rodriguez et al. 2012), and its northern part which is enclosed by an almost impassable electric fence (although some animals do get through) that separates it from the city.

Leopard hunting strategies are therefore governed by the abundance of prey, by the availability of new hunting grounds and by the capacity of the landscape to offer the animals conditions for successful hunting. In this respect, the differences between the two urban ecosystems are significant, with Nairobi's being clearly less attractive than Mumbai's. The urban fabric is denser in Mumbai than in Nairobi and the interpenetrations between the park and areas of high population density are greater in India than in Kenya. More than 500,000 people were living in SGNP in 1995, and probably 120,000 still do so today. Aarey Colony is thought to be home to almost 20,000 Adivasis and 30,000 slum dwellers, fairly easy prey given the poor protection afforded by informal housing and the open areas around the settlements. Adivasis' use of natural resources is important: they compete for space with leopards. In Nairobi, by contrast, there are no houses in the park, and the Bangladesh slum, on the edge of the park, has only one or two hundred inhabitants, whereas Kibera, the city's largest slum, has a population of 250,000 but is relatively distant from the park (Desgroppes 2008). Nairobi's landfill sites contain almost no organic matter and are located far to the east of the city, whereas in Mumbai waste management is inadequate and garbage piles and bins are present in every neighbourhood, encouraging the proliferation of animals such as dogs, rats and pigs which are all attractants for leopards.

The degrees of interpenetration between urban areas and parks thus have a very clear impact on the structure and functionality of the ecosystems in which leopards operate. These ecosystems cannot be considered as natural environments, but should rather be seen as hybrid "naturban" milieus, where dogs occupy a position in the food chain that links the wildest and the most urban parts. The relation of humans to the leopard and the risks associated with it are therefore a secondary outcome of the big cat's predation on the canid, but this does not remove the specifically social dimension of the human link to the animal world and in particular the continuum between the domestic and the wild apparent in that link. Paradoxically, therefore, the canine presence invalidates a dichotomous vision of a conflict between a wild animal and human beings, and a vision of human beings moreover as separate from nature in their urban existence. Instead, it prompts us to identify the connections between those two spheres, in which the forms and varying effectiveness of spatial and species purification (porosity of interstices, presence/ absence of domestic animals) is less a technical and administrative question than, as we will see, the reflection of different visions of the world. 


\subsection{Methods of Managing the Problem: The Law of Unintended Consequences}

\subsubsection{Recognition of Ecosystem Services in Nairobi}

In both countries, the national park management services are known for their paramilitary character and their exalted vision of their role, which tends to be reflected in a certain lack of coordination with other actors and in often authoritarian decisions. Visitors to Nairobi National Park (NNP) are welcomed by a monument to the dead of the KWS, and by the statue of a heavily armed ranger. Many of these rangers are almost trained soldiers, who have notably followed a nine-month course in difficult conditions in Maniani. In Mumbai, the entrance to the national park is very different: no monument to the dead but a large fresco showing characters from Walt Disney's Jungle Book. However, appearances can be deceptive. Not only does India's Forest Department (FD) generally yield nothing to its Kenyan equivalent in terms of self-belief, not to say arrogance, but its management is even more rigorous, unwilling to leave anything to the municipality.

In Nairobi, the KWS organisation chart includes a Community Unit, responsible for relations with the outside world, ${ }^{5}$ both rural and urban citizens, and the intervention unit against so-called problematic animals recruits Maasai, largely from Kitengela: the risks of collusion resulting from the social proximity between these recruits and the inhabitants seem less than the advantages of having rangers capable of negotiating with and understanding the needs of the pastoralists. Two decentralised sites in the heart of Maasai territory, in Kipeto and Kitengela, are also home to members of the Community Unit. There is no equivalently "social" approach in Mumbai, where it is only in recent years that the FD has begun recruiting Adivasis - but only for temporary contracts and menial tasks (see Chap. 6). There is no unit that specialises in managing the problems of relations with the city, and for the Territorial Division (which manages forestry issues outside SGNP), the problems are intractable: one Range Officer we spoke to even compared the situation to the war in Kashmir and the Line of Control between India and Pakistan. ${ }^{6}$

This is undoubtedly a matter of political will, but also a question of resources. The FD is under-resourced, because India, despite its ostensible interest in protected areas and iconic species such as the tiger, allocates proportionally fewer resources to protecting fauna than does Kenya. By contrast, fauna is a fundamental resource for Kenya, where tourism depends largely on wildlife, and where a significant percentage of the economy (17\% of GDP) relies on this tourism industry. The nation and ethos of Kenya are partly constructed around the idea of Nature, both symbolically and economically the country's primary showcase - we will see that this also has consequences for the practices of citizens and the environmental

${ }^{5}$ Headed by the Community Warden, it also includes two corporals, two rangers, and a driver.

${ }^{6}$ Interview, February 13, 2013. 
standards disseminated through education. Since the days of the first colonial conservation policies, nature was a fundamental imperial priority in the dominance of the British elite in this part of the world, subsequently transformed into a national priority adopted by Kenya's leaders and maintained by NGOs to the present day (MacKenzie 1988; Matheka 2005).

This explains why in 2005 the KWS accepted the program launched by a partly American NGO, The Wildlife Foundation, to finance two initiatives in NNP. First, the payment of compensation to pastoralists who had lost livestock to attacks by carnivores. True, the compensation was only partial, and the programme was ultimately suspended, but the idea was later implemented in the Maasai Mara reserve (Osano et al. 2013), and then in mor gerous form at national level, by the Wildlife Act of 2013. In this respect, NNP has proven to be a laboratory — and its urban location, in the country's capital, has undoubtedly contributed to this role (see Chap. 14).

The second initiative was the payment of compensation to Maasai who undertook not to close their pastures to the south of the park and not to kill wild animals that had attacked their livestock. Here again, the initiative (2000-2012) fizzled out, but the idea was there: to pay for the ecosystem services provided by pastoralists who attracted wildlife by maintaining the pastures. NNP is a central space, politically dominant, but ecologically dominated by a whole hinterland through which wildlife travels: it depends on this hinterland, especially in the dry season, to be able to accommodate large numbers of animals.

There is nothing of this in Mumbai. With a few exceptions, the FD remains obstinately committed to a separation between park and city that no one may circumvent: neither people (it was out of the question that compensation should be paid to inhabitants of the park who have fallen victim to leopards), nor animals (leopards are supposed to stay in the park). This is a long way from the notion of ecosystem services, even though some foresters acknowledge that before its confiscation, the livestock held by the Adivasis in the current perimeter of the park maintained the pastures: the attempts at reforestation of almost the entire park were misconceived, in that they ran counter to the needs of the herbivores, potential prey for leopards. Fortunately, maintenance of pasture lands is now back on the agenda in the latest development plan.

\subsubsection{Carnivores have never been modern}

In Mumbai even more than in Nairobi, the carnivore represents a dual conceptual problem. First, it upsets the nature-culture dichotomy that underpins the delineation of protected areas and the separation between city and park. Indeed, following Latour (1993) and studies on the history of nature conservation (Adams 2004; Brockington et al. 2008), one may advance the idea that spatial arrangements such as national parks obey a twofold imperative of purification: by means of specific spatial arrangements, animals are rendered radically different from humans. Nonetheless, these arrangements produce hybrids that disrupt the grand categories through which "naturalism" operates (Descola 2013). The leopards that attack 
humans in Mumbai are a typical instance of these hybrids and show how hard it is for the naturalist and "modern" model to work. ${ }^{7}$ It is a problematic issue for leopards and other potentially dangerous animals, which are seen not only as undomesticated, but also as non-urban. In this, the two cities reveal two different trajectories: the long-term resilience of a certain modern purification in Nairobi, and the historical weakness of that purification in Mumbai. In India, the issue is one of a history that remains resistant to spatial purification, understood as an effective and functional ("pure") segregation between nature and city. Which does not mean that tensions and diverging views do not exist in Mumbai today.

For most people and park managers, big cats are or should be living in protected areas. Some of the leopards released in SGNP in the late 1990s had been caught in densely populated countryside and relocated to the park because it was imagined to be their "normal" habitat. Animals outside protected areas are supposed to be "stray" animals that must be "rescued", i.e. trapped and deported to protected areas. While few people in Mumbai dispute the fact that a protected area such as SGNP should contain leopards, as soon as the animals move slightly outside, it is considered a problematic exception that cannot be permanent. ${ }^{8}$ In their survey of scientific literature on large felids in India, Ghosal et al. (2013) found that $90 \%$ of the published papers are based on research in and around protected areas, whereas about one-third of India's tigers live outside them - the proportion for leopards being probably higher. "The close association of felid research with PAs is also an outcome of these purification and translation processes discussed [by Latour and others]. Reports of large felids outside PAs and in multi-use landscapes are interpreted as the result of degradation of habitat and prey base within Pas....There is thus a 'correct place' for large felids, and their presence outside this moral geography is regarded as an abnormality" (p. 2678).

The result of these representations: in Mumbai, just as the slums need to be moved out of the park and the demolition of Adivasi villages remains on the official agenda, leopards that are deemed to have left the park must be returned to it. It is not only the political desire to limit the risks of conflict attributable to the FD, but also the belief in the non-urban character of these animals, which encourages the capture of any leopards seen outside the park. Such practices are counterproductive: not all such animals survive the trauma of capture, and competition with leopards already present in the areas of relocation can prove dangerous to the introduced

\footnotetext{
${ }^{7}$ See also Harrisson (1993): "Forests mark the provincial edge of Western civilization, in the literal as well as imaginative domains .... We call it the loss of nature, or the loss of wildlife habitat, or the loss of biodiversity, but underlying the ecological concern is perhaps a much deeper apprehension about the disappearance of boundaries, without which the human abode loses its grounding." Leopard is to contribute to this transgression of boundaries....

${ }^{8}$ Although in charge of SGNP and the neighbouring Tungareshwar Wildlife Sanctuary, the FD does not appear to be very interested in enhancing the connectivity between these two forests. Yet, creating corridors and helping leopards move within a larger network of forests could help release the pressure on the national park by decreasing its population of leopards. Also, since mobility is critical to leopard survival, geographic isolation-like in the case of the SGNP - can lead to inbreeding, depression and increased extinction risk of the leopard population (Edelblutte 2016).
} 
animal (Edgaonkar and Chellam 1998), and stress may lead to heightened aggression (Athreya 2011). It was only after 2004 that the FD realised its error and stopped importing leopards - at the same time preventing further human fatalities, with the exception of a few rare tragedies.

In Nairobi, animal relocations also take place, but they are carried out with much greater circumspection. Above all, they apply primarily to herbivores, in the expectation that they will reproduce and attract big cats. Since the southern area is open, there is no clearly defined overpopulation threshold, in particular for leopards, since they are more mobile than lions (which tend to find themselves trapped in the national park in the rainy season when the herbivores have left).

\subsection{Media Exposure and Perceptions: Social and Cultural Factors}

\subsubsection{Media Hijacking}

Without wishing to underplay the human tragedies, there is no doubt that deaths in the slums of Mumbai are exploited by local political operators, in a very lively Indian democratic scene where the rate of voter participation is inversely proportional to income and qualifications. In this "political society", which does not really operate as a "civil society", so dominant is the role of political parties (Chatterjee 2004) $\overline{\mathbf{2}}_{\mathbf{2}}$ attacks in the slums, and also in the Adivasi settlements, generate big aftershocks. At the opposite pole of society, in the wealthy residences on the edge of the park, the attacks also make a lot of noise, because of the dual connections individuals enjoy: between each other, via mobile phones and "social networks"; and vertically, with the political community, senior local civil servants and the media. Although rarely the direct victims of attacks, wealthy Mumbai residents are the first to alert the authorities and the media. ${ }^{9}$ Is not the "minor news item" the indicator of the emergence of a media society? Ultimately, Mumbai is experiencing a twofold process: the politicisation of attacks within poor populations, and media exploitation by the rich populations. The combination of these two processes explains the exceptional impact of the fatalities.

\footnotetext{
${ }^{9}$ They are also the first to call out on tribals undertaking illegal activities. During a field trip, E. Edelblutte visited a tribal village inside the park where a family was building a new house with better material than thatch since they had too many intrusions of leopards in their old house. A forest officer had to investigate after receiving a call from high-rise building residents living nearby who had reported "illegal activity from tribals". The officer, empathetic towards their situation, just gave them a warning and told them to be more discreet, so that he does not get other calls from urban residents. Also note that Adivasi sometimes "use" leopard attacks to expose their living conditions and ask for better amenities (especially electricity, waste management system and public lighting) (Edelblutte 2016).
} 
In Nairobi, the situation is less tense, as much because of greater acceptance of wildlife, as because of the rarity of attacks on human beings. Nonetheless, as the commander of the KWS's Problematic Animal Control section explains, in the event of an attack, "the aim is to arrive before reporters, television, politicians, which is not always possible since we may have no vehicles or arrive too late. But the main thing is to listen to people, to provide reassurance. It is undoubtedly more difficult to deal with the Maasai than with the wealthy populations of Karengata: because they are armed, and in groups, and if they say that they are going to kill a lion, they will kill it, in ten minutes. You are talking to somebody who has lost animals! The definition of the conflict between human and wildlife is when you go to a situation where people are angry with you. But the situation has improved in the 12 years I have been here, there is more dialogue". ${ }^{10}$ (We will see that this optimism has recently proved hollow).

In addition, the requests for intervention received by the KWS are socially and spatially very different: people living in Nairobi, particularly those in the wealthy western part, usually telephone before an attack, to report the presence of an animal, whereas the Maasai living around the city always call afterwards, to demand its capture, or perhaps compensation. The Community Warden claims that rural problems are the priority for the KWS, although calls from city dwellers represent half of reports: this is because the issue of conservation is less urgent in the city than in the countryside south of Nairobi. "It would make no sense to organise meetings in Langata on monkey problems! Those people contribute little to conservation, whereas the people in the south are key partners: they accept not to sell their land, they make the park unique, they don't fence or grow crops that much. We need to keep on engaging them". ${ }^{11}$ This choice is not necessarily a choice in favour of the poorest: many of the Maasai are big landowners and economically powerful figures. However, it would seem that the situation is worse in Mumbai, where the powerful and the poor get very different treatment. In India, with the exception of attacks on people, when even the Adivasis alert the FD or the police, tribal people go unheard. Slum dwellers have no telephones or lack the courage to use them, whereas people from the wealthy residential areas will call even though they face less risk.

\subsubsection{Perceptions}

The crucial question is how the inhabitants behave in response to wild animals. Around Mumbai National Park, but also in India's zoos and reserves, many people exhibit particularly inappropriate behavior, such as shouting or throwing stones at the animals. Some are absolutely determined to take photographs with their mobile phones, whatever the risk, while others succumb to noisy panic, instead of letting

\footnotetext{
${ }^{10}$ Interview, August 2, 1014.

${ }^{11}$ Interview, July 21, 2014.
} 
the animal continue on its way. This causes stress to the animals, which may respond violently to human beings, either immediately or subsequently, All the evidence that the simple "exposure to nature" during park visits is not enough to inculcate ecological values and behaviours (Mawdsley et al. 2009): most city dwellers have no notion of nature as heritage (to be respected) or as a resource (to be managed). It is a matter of perception of the environment, and more specifically of leopards: this is an essential difference between the two parks - in Nairobi, people have greater respect for wildlife and, while still afraid, have a general sense of how to behave if they encounter wild animals. "People in Kibera", a woman from the slum told us, "are aware. They had gone into the park with their school, they know that we must save lions outside the park if we want to see lions in the park". ${ }^{12}$

Nonetheless, this requires some qualification. Exceptionally, in March 2016, two lions were killed in two days in the south and east of the park, the second with a spear (suggesting Maasai reprisals), and the first by a KWS ranger who purportedly had no choice, since the anesthesia services were delayed and the crowd around the animal was making it aggressive. In this, the dry season, lions do not usually leave the park, but they were perhaps disturbed by work on the new bypass and railway line, which had apparently also caused the shutdown of electrification on the eastern fence. This also shows the limits of the self-control of Nairobians at the sight of carnivores in the city: as in Mumbai, they may respond by shouting, exciting the animal, or wanting to take photographs. The videos posted after the drama record the hooting of excited motorists. Nonetheless, accidents are less frequent in Nairobi, a difference partly explained by the different role played by wildlife in the national ethos of the two cities.

In Mumbai, two parallel initiatives are underway to try to reconnect the urban population with the animal world. The first was started by an activist previously affiliated to the Bombay National History Society, Krishna Tiwari, who is working with his group to run awareness-raising sessions on the danger of leopards in the slums and the Adivasi settlements. Signs posted on walls or trees explain how to stand tall to impress the animal in the event of an unexpected encounter, and encourage people to stick to certain times of day etc. (Photo 7.1). The other initiative is run by an association that is trying to work with the national park authorities, despite the reluctance they have shown until recently to collaborate with users or ecologists: Mumbaikars for SGNP (MfSGNP) works in schools to raise awareness amongst children and parents, as well as with police stations (often the first to be alerted in the event of an attack). MfSGNP also organises neighbourhood meetings, often in middle-class areas, to try to convince the inhabitants that leopards are not dangerous if one follows certain rules of behaviour: it is capturing them and releasing them in an environment that is not their territory that makes them aggressive.

${ }^{12}$ Interview, July 20, 2014. 
Photo 7.1 "How to avoid leopard conflicts. Do's and don'ts in leopard areas" (Poster pasted in a tribal hamlet by the Forest and Wildlife Conservation Centre)

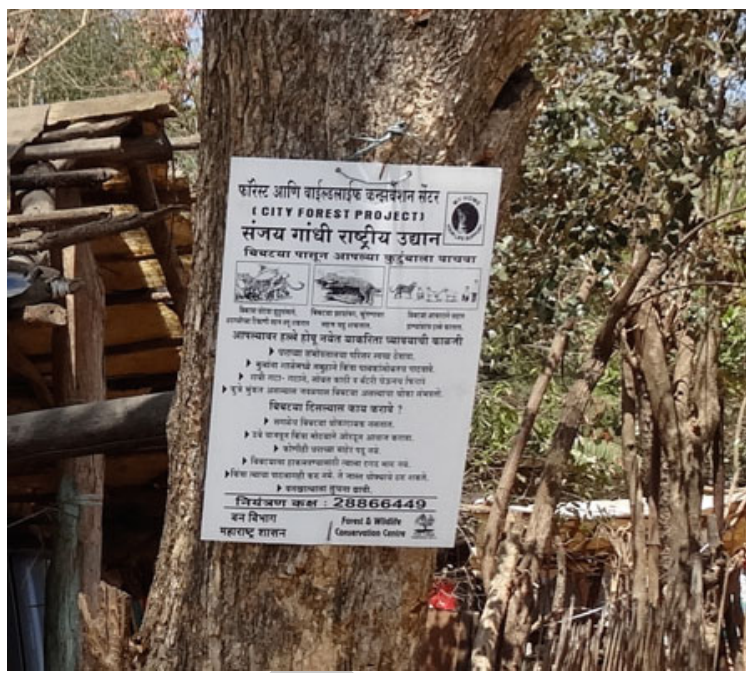

What we see here, therefore, is the emergence of an ambiguity linked to urban sociopolitical structures. In principle, the majority of the middle class or wealthy urban populations share a "naturalist" ontology, based on the modern dichotomy between nature and society - in this case, between park and city. For Mumbaikars, apart from a recreational area open to visitors, an urban national park should be less "urban" than "national", and above all "natural". So leopards have no legitimacy outside the boundaries of the park, for reasons of safety of course, but also because these animals have their territory in the sphere of nature, not of the city. In Mumbai, with the exception of a few activists mostly from the middle or wealthy classes, the majority of the population - both rich and poor - seems to have little attachment to urban (wild) fauna and more generally to the ecological project of the national park. In terms of ecological perspectives, the social contrasts are greater in Nairobi: whereas almost all the inhabitants of the Kibera shanty town seem to be frightened of wildlife, or at least not much interested in it, ${ }^{13}$ those of the smart Karen district include plenty of households favourable to nature conservation and attracted to this very green area by the very proximity of the park and the prospect of seeing wildlife roaming free.

In both cities, is a sharp contrast in the Adivasi or Maasai minorities. For these two groups, there is no radical difference between human nature and animal nature, let alone a hierarchical order: they are practitioners of a blend of "animism" and "analogism", as classified by Descola (2013). Both the Adivasi and the Maasai consider themselves to be an integral part of an ecosystem, of a totality, which excludes neither humans nor animals. Sharing in this respect the perspective of many

\footnotetext{
${ }^{13}$ Animals can be associated with black magic. We were told about a hyena that had been sent to kill an enemy's livestock, but on the way had attacked the interviewee's female cousin. The latter agreed that "yes, we need national parks... because animals are destructive, and otherwise elephants could kill people". The park as protection for people, not wildlife....
} 
Indian ecologists we met in Mumbai, they assert that God created an environment in which we cannot select certain elements and reject others (see Chap. 6). "The wildlife is our animals. If they kill one of our people we kill them. But we love them. We stay with them". ${ }^{14}$ Wild animals are an integral part of the Maasai social system and of the mythology of the Adivasis: the Warli Adivasis of SGNP venerate Waghoba, the tiger-god, whose temple is in the park. The leopard is considered to be Waghoba's "little brother", and the two animals are often spoken of as one On the contrary, for many non-tribal Hindus the leopard has no prestige since it is the vehicle of any god - unlike the tiger who is attached to Durga, Parvati or Shiva deities. (Yet in Himalayan states the leopard is regarded as the vehicle of the Goddess). For some of the Adivasis interviewed, human fatalities are the consequence of a lack of respect for the leopard. The leopard's integration into the value system can also correspond to a spirit of resistance (Ghosal 2012, 120). Are not carnivores the ultimate "weapons of the weak"? (Scott 1985). In Nairobi, the KWS told us that some lions are killed less in reprisal than to send a message and attract attention: in this case, the conflict is not so much about dead livestock than about delays in compensation, or even about a well that the KWS had promised to help dig.

\subsection{Carnivore Management by the Park, by the City, or by Both: A Matter of Postmodernity or A-Modernity?}

Since wild carnivores are unaware of the official boundaries between city and park, there are in principle three ways of managing fauna outside the protected area: either the park is responsible for management everywhere, even outside its jurisdiction (type 1), or it is the business of the municipality (type 2), or the two institutions manage it together (type 3 ). In both countries, wildlife belongs to the state, and therefore falls under the authority and jurisdiction of the KWS and FD. However, it is only in Nairobi that the service invariably operates in the city (type 1). There is no dedicated hotline, but the KWS's telephone number is generally known, and people living in the areas most frequented by wildlife often have the private numbers of the Community Warden or rangers. Unlike in Mumbai, the police have little involvement with wildlife incidents. Ultimately, this type of management has proved quite effective-though the accidents of March 2016 seriously blotted the record-and the urban authorities certainly don't complain about being uninvolved in the issue. ${ }^{15}$

\footnotetext{
${ }^{14}$ Interview in Maasai Mara, March 24, 2012.

${ }^{15}$ Locally, the KWS can be supported by other actors. For example, fauna in the Ngong Road Forest are partially managed by the Ngong Road Forest Sanctuary Trust, which sometimes also calls upon the Kenya Forest Service in the event of problems. Moreover, the recent decentralisation has given greater powers to the counties in the management of biodiversity (see Chap. 8), and the KWS could probably do more to gain support from elected officials.
} 
Logically, since India's FD was not designed to operate in the urban environment, the second type of management - by the city - should be the mode that prevails in Mumbai. However, this is not the case and, in our opinion, here lies the heart of the problem. The city ignores the park, to the point that its inventories of open spaces completely elide any mention of the existence of this $104 \mathrm{~km}^{2}$ area over which it has no oversight. As a result, until recently, when an inhabitant complained to the urban authorities about a leopard, he was referred to the FD on the grounds that the leopard belonged to the park, and that it was therefore up to them to handle the problem. However, when contacted, the FD would take the view that a leopard in the city lay outside its jurisdiction, and would refer the complainant back to the city authorities. It was only in 2012 that a joint telephone hotline was set up by the FD and the urban authorities, and that combined meetings of both institutions began to be held. Leopards have proved to be excellent go-betweens! (Landy 2017). However, these remain fragile and ad hoc structures, and there is no formalisation of relations with the city in the FD's organisation chart or activities.

Mumbai therefore has much to learn from Nairobi, whose approach suggests the benefits of granting compensation to limit reprisals against animals. It also showsalthough the role of coercion in KWS's policy should not be underestimated-the need for mitigation, dialogue and coordination, and the advantage of a "proactive" prevention policy. For FD employees, this policy should be accompanied by the inclusion of a little social science in their training curriculum, to raise awareness of the human factor, of which they generally remain very ignorant.

As we can see, while both countries express the same concern for the protection of fauna and a wilderness often approached from a highly preservationist perspective, the political will in India is less strong, with the result that both financial and political resources are lacking. It is therefore for material as much as political reasons that the FD finds it hard to operate in the urban conurbation of Mumbai. Fortress conservation remains dominant in official rhetoric in both Nairobi and in Mumbai, but in practice the KWS - as an instrument of that fortress - manages the urban boundary with an "efficiency" that is often authoritarian: this management of "purified" areas notably includes operations beyond the physical boundaries between the park and the city. In Mumbai, by contrast, actual practices contradict preservationist rhetoric. The FD's difficulties in intervening outside the park are not a sign of the strength of the fortress, but of its political weakness, since it has difficulty in managing the interface between humans and nature in a way that keeps them separate. 


\section{Baboons and Relocation in South Africa}

In Tijuca Park in Rio de Janeiro, agoutis and then howler monkeys have been reintroduced since 2010, but these animals remain scarce in a park that is otherwise devoid of large mammals. Table Mountain National Park offers a more interesting comparison with the Kenyan and Indian cases. It differs from the parks in Nairobi and Mumbai in that it does not form a single block, but several sections, each separated by road arteries or residential areas. It is also distinctive in being the country's only park that is not fenced, though paradoxically it directly borders the city, either via residential neighbourhoods or the edges of the city center itself.

This park contains neither leopards, nor any other predator that is really dangerous to human populations. It is home to a few caracals (Caracal caracal), but these cats are particularly discreet, not very wild, and too small to present a real danger to human beings. Large bovidaes (e.g., eland, bubal, etc.) and zebras populate the most southern part of the park, in the Cape of Good Hope section, but this zone is inhabited and fenced. In the rest of the park, the most problematic and potentially dangerous species is the Cape Baboon (Papio ursinus), the largest of the baboon species, which can weigh up to $45 \mathrm{~kg}$. While these monkeys do not present a direct threat to human beings, they can become very aggressive when attracted by food, not hesitating to enter cars or houses, or to make incursions into the Constantia vineyards which border the eastern edge of the park, causing very significant economic damage. These protected animals, now free of predators since the local disappearance of the leopard, have in fact become too numerous (around 400 on the peninsula): a degree of food pressure is therefore pushing them towards the city and resources that are fairly accessible, especially as the disappearance of pine trees has deprived them of a food source (pine nuts) and a habitat (they often lived in the trees). Tour operators and visitors want to have baboons close to roads, whereas at the same time, for safety reasons attempts are made to keep baboons out of the main visited areas: these animals are both an attraction for tourism and a threat it.

Despite the means available to local authorities, this animal control problem is not being adequately managed. There is a baboon management plan that involves the city, the park and the regional Nature Conservation Department (CapeNature), but this focuses on problem individuals (which may be frightened off, relocated or euthanised, depending on the circumstances) and offers no strategic solution. In particular, there is no urban edge policy. None of the simple measures that exist to limit baboon incursions into inhabited areas is applied locally. The construction of fences along the houses at the edge of the park, and the use of baboon-proof waste bins, are neither funded nor compulsory. Apart from the case of the baboons, there are no policies for managing the park's ecological boundaries (see Chap. 8). Nothing, for example, prevents individuals keeping cats or invasive plants in their gardens, though these may have a crucial impact on environmental dynamics within the park. 
It may be that this lack of coordination is a consequence of difficulties in the joint management between the administration of Table Mountain Park and Cape Town municipality in the last few years-(see Chap. 20). However, these are genuine difficulties, partly the result of a specifically South African vision of the relation to nature, which is about more than a simple issue of local management. More specifically, they arise from a particular attitude to the boundaries that run across the country, designed both to separate social groups from each other and human beings from natural milieus. It is well known that the purpose of the establishment of apartheid in the mid-twentieth century was not only to keep social groups physically separate, but also to create an institutional segregation designed to maintain distinctions, even in cases where the black, Indian or colored populations might have practiced similar lifestyles (notably in urban and/or educated populations) and therefore claimed political equality. In this respect, the history of South Africa has been characterised both by highly controlled boundaries and by fear of their transgression. Against this general background, nature - in the form of parks primarily created to protect wildlife - has contributed to that spatial segregation by expelling marginal populations and then denying them access to those spaces. At the same time, protected wildlife itself constituted a potentially dangerous actor, capable of transgressing boundaries. Paradoxically, these concerns regarding transgression have persisted into the democratic transition, but shifted to the economic sphere. In this sense, intrusion, whether human or animal, constitutes a recurrent dimension in South Africa's political imagination. To employ the terminology used in this chapter, modern purification in South Africa has always been influenced by a threat of intrusion (Rodary 2016).

Apart from the construction of multiple barriers (picnic areas fitted with baboon-proof fencing), the material response to these fears in the sphere of wildlife conservation has primarily taken the form of relocation policies. Since the 1970s, this practice of wildlife relocation has become a highly lucrative business in the country. It affects all sectors of conservation, from private wildlife ranches to protected public spaces. In Table Mountain Park, this vision-which prioritises forced relocation over the negotiation of boundaries - is reflected, as we have seen, in a neglect of the issues relating to the boundary between park and city. It is also apparent in the direct management of the baboons, which are periodically transferred by truck to rebalance the populations in the south and north of the park. Rangers armed with firecrackers or paintball guns are tasked with intimidating the most intrusive individuals, and operate in the most touristic areas of the park and in isolated residential areas. And the problems of genetic impoverishment affecting the baboon population, which is divided into two groups by the residential area linking Noordhoek to Fish Hoek, are managed by regularly moving certain individuals from one group to the other. The creation of a corridor that would allow the animals to move from north to south is not on the agenda. This gives some idea of the problems - both institutional and symbolic - that may also arise in the event of 
a connection between the national park and the city's reserves, isolated in an urban environment that has plenty of connection issues to tackle other than those of wildlife.

Estienne Rodary

\subsection{Conclusion}

Our initial hypothesis was that a different form of park management, more in harmony with that of the city, might explain the absence of leopard attacks on humans in Nairobi. We speculated that the actors in the two spheres coordinate their efforts to ensure better oversight of wildlife. This hypothesis was not confirmed. Instead, we saw the importance of factors such as predation by leopards on populations of domestic dogs, the landscape configurations of the interfaces between park and city, and the diversity of representations of nature or social disparities, which generate differing vulnerabilities. This leads to a two-level conclusion regarding the role of the national trajectories in these countries of the Global South in respect of environmental concerns and their contribution to the new ways of understanding our relation to nature.

Leopards force us to consider in a new light the old controversy about environmentalism in developed countries versus the Global South. According to Guha and Martinez-Alier (1996), the theory of postmaterialism and the idea that only industrialisation and urbanisation lead to separation from nature, contributed to the belief that the deliberate environmentalist attempt to protect nature is only possible in developed countries. As Frykman and Löfgren (1987) wrote regarding Sweden: "One of the preconditions for a more Romantic and sentimental view was... the gradual withdrawal from an active or productive use of nature" (p. 78). Sentiment regarding animals, in particular farm animals, increased: "It was love at a distance." "Nature must first become exotic in order to become natural" (p. 83). However, Guha and Martinez-Alier disputed the view that the resistance to the creation of protected areas in developing countries is attributable to a lack of environmental awareness in their populations, arguing that the cause is simply a political conflict directly linked to the social marginalisation brought about by the establishment of protected areas. While Northern environmentalists tend to focus on nature conservation, Southern environmentalists address the interrelations between poverty and environmental degradation.

However, the terms of this controversy are being totally rewritten by studies such as this one, conducted in emerging economies where a growing elite is adopting a westernised Weltanschauung, while the majority of the population remains poor. We provide new answers to the controversy as to whether environmentalists are to be found only in developed countries or whether "empty-belly environmentalists" (Guha) exist in the Global South. At first sight, the former claim 
may seem to be validated by the SGNP case. On one side are middle-class environmentalists, whose way of life and culture are highly westernised; on the other, the slum dwellers who want to get rid of the leopards and are not interested in the national park. But where should the Adivasis or the Maasai be positioned on this "ladder of environmentalism", or bourgeois anti-environmentalists? It is clear that the question should not be posed in binary terms, since numerous types of "environmentalism" coexist. In Mumbai or Nairobi, as in developed countries, there are several types of middle-class environmentalism: the environmentalism of nature and wilderness has little to do with that of social ecology and environmental justice, nor with that of opposition to waste and industrial or electromagnetic pollution in cities (Blanchon et al. 2009). The first type of environmentalist would defend the leopards, the others not necessarily (Wolch 1998). Guha and Martinez-Alier are right to highlight the environmental mindsets of the Chipko activists and other peasant or indigenous movements; however, they should not set up the global North and South in opposition to each other, since many Indian environmentalists are quite close to the tenets of wilderness ecology, while often being "anti-poor". In contemporary India and Kenya, there are plenty of full-stomach environmentalists.

Ultimately, it is not because park and city are more integrated and harmonious in Nairobi than in Mumbai that there are fewer fatal attacks by carnivores. It is because landscape configurations and the availability of prey differ, but also because the big divisions of modernity between nature and culture have been tackled as a political issue in Kenya, whereas they have remained marginal in India's spatial representations. The paradox, therefore, is that though the two institutions responsible for the parks are formally organised on the basis of a very clear separation between the spheres of wild nature and the social world, the Indian trajectory has not really led to policies capable of establishing the boundaries that this separation entails.

This produces an apparent paradox, since current nature conservation policies around the world are moving towards greater integration, raising the question of whether Mumbai is not in fact better placed to pursue such integration than is Nairobi. The recent changes in nature conservation policies in Kenya, involvingas we have seen - a greater use of incentives, raise the issue of whether this is a genuine paradigm shift in conservation, or rather the empirical adaptation of an institution that seeks to perpetuate the national park model at any cost. In other words, far from making breaches in the "fortress", what we have is perhaps something of a preventative strategy conducted to maintain that fortress, not by extending its walls to annex further territory, but by building fences that are more social in kind and less visible. By incorporating conservation principles into the habitus of the population, the aim is to establish a new form of environmentalism as defined by Agrawal (2005): the creation of "environmentalist subjects" who will support conservation policies after adopting the imperatives promulgated by the authorities at all scales (e.g., national authorities, international NGOs with a strong presence in Kenya, etc.). In Mumbai, as we have seen, these policies were largely absent. It is not just a matter of education (there are as many school visits to the SGNP as to Nairobi Park, although ecological values are much better taught in 
Kenya): in Nairobi, payment for ecosystem services, the creation in 2014 of a Management Committee including representatives of the "communities" and companies, the increase in visits by Kenyans to the park, where foreigners now represent a minority of visitors, the practices of companies that take their clients on trips to the park, have all helped to forge new forms of "mobilisation for nature" (Rodary 2009).

What we see in Nairobi, therefore, is an "adjusted modernity" rather than a genuine postmodernity that seeks to break down the dichotomies between nature and society, park and city. The fortress remains, and the recent "back to the barriers" movement, which promulgates a stricter conservation (Hutton et al. 2005), along with the revival of military anti-poaching policies in East Africa (Neumann 2004), are evidence that the tensions between integration and segregation remain extremely sharp within the conservationist world. In Mumbai, most city dwellers are without nostalgia for the countryside or forest from which many originate. They are fans of modernity, and the "concrete jungle" corresponds to an ideal largely founded on a progressive vision that places no value on the state of nature. Nonetheless, their spatial practices of proximity to animals, both domestic and wild, provide a glimpse of forms of connection and integration with the natural world which, even though they have no institutional correlative, may correspond-often inadvertently - to the objectives of integrated conservation, the "new ecology" and the incursion of nature into the city (Wolch 1998).

\section{References}

Adams, W. M. (2004). Against extinction: The story of conservation. London: Earthscan.

Agrawal, A. (2005). Environmentality: Technologies of government and the making of subjects. Durham; London: Duke University Press.

Athreya, V., Odden, M., Linnell, J. D. C., Krishnaswamy, J., \& Karanth, K. U. (2014). A cat among the dogs: leopard Panthera pardus diet in a human-dominated landscape in western Maharashtra. India. Oryx, 50(1), 156-162.

Bailey, T. N. (1993). The African leopard. Ecology and behavior of a solitary felid. New York: Columbia University Press.

Baviskar, A. (2002). The politics of the city. Seminar, 516, 40-42.

Benhammou, F. (2007). Crier au loup pour avoir la peau de l'ours. Une géopolitique locale de l'environnement à travers la gestion et la conservation des grands prédateurs en France. $\mathrm{Ph}$. D., Paris: ENGREF.

Blanc, N., \& Cohen, M. (2002). L'animal. Une figure de la géographie contemporaine. Espaces et Sociétés, 110-111, 25-40.

Blanchon, D., Moreau, S., \& Veyret, Y. (2009). Comprendre et construire la justice environnementale. Annales de Géographie, 1(665-666), 35-60.

Brockington, D., Duffy, R., \& Igoe, J. (2008). Nature unbound: Conservation, capitalism and the future of protected areas. London: Earthscan.

Buller, H. (2013). Animal geographies I. Progress in Human Geography, 38(2), 308-318.

Buller, H. (2014). Animal geographies II: Methods. Progress in Human Geography, 39(3), 374384. 
Buller, H. (2015). Animal geographies III: Ethics. Progress in Human Geography, 40(3), 422430.

Butler, J. R. A., Linnell, J. D. C., Morrant, D., Athreya, V., Lescureux, N., \& Mckeown, A. (2013). Dog eat dog, cat eat dog: Social-ecological dimensions of dog predation by wild carnivores. In M. E. Gompper (Ed.), Free-ranging dogs and wildlife conservation (pp. 117-143). Oxford: Oxford University Press.

Chatterjee, P. (2004). The politics of the governed: Reflections on popular politics in most of the world. New York: Columbia University Press.

Descola, P. (2013). Beyond nature and culture. Chicago: University of Chicago Press.

Estebanez, J., Gouabault, E., \& Michalon, J. (2013). Où sont les animaux? Vers une géographie humanimale. Carnets de géographes, 5 (online).

Edelblutte, E. (2016). Landscape and political ecology approach for long-term conservation of leopards (Panthera pardus) in a human-dominated landscape, India. Report for UNPEC and EVS lab, University of Lyon 2. Unpublished.

Foster, J., \& COE, M. J. (1968). The biomass of game animals in Nairobi National Park, 1960-66. Journal of Zoology, 155(4), 413-425.

Frykman, J., \& Löfgren, O. (1987). Cultural builders: A historical anthropology of middle-class life. Newark: Rutgers University Press.

Galhano Alves, J.-P. (2002). Vivre en biodiversité totale. Des hommes, des grands carnivores et des grands herbivores sauvages. Deux études de cas: loups au Portugal, tigres en Inde. Ph.D., Marseille: University of Aix-Marseille.

Ghosal, S., Athreya, V. R., Linnell, J. D. C., \& Vedeld, P. O. (2013). An ontological crisis? A review of large felid conservation in India. Biodiversity and Conservation, 22(11), 2665-2681.

Guha, R. (1989). Radical environmentalism and wilderness preservation: A third world critique. Environmental Ethics, 11(1), 71-83.

Haraway, D. J. (2008). When species meet. Minneapolis; London: University of Minnesota Press.

Harrison, R. P. (1993). Forests: The shadow of civilization. Chicago: The University of Chicago Press.

Hayward, M. W., Henschel, P., O’Brien, J., Hofmeyr, M., Balme, B., \& Kerley, G. I. H. (2006). Prey preferences of the leopard (Panthera pardus). Journal of Zoology, 270, 298-313.

Hutton, J., Adams, W. M., \& Murombedzi, J. C. (2005). Back to the barriers? Changing narratives in biodiversity. Forum for Development Studies, 2, 341-370.

Khorozyan, I., Ghoddousi, A., Soofi, M., \& Waltert, M. (2015). Big cats kill more livestock when wild prey reaches a minimum threshold. Biological Conservation, 192, 268-275.

Landy, F. (2017). Urban leopards are good cartographers: Human-nonhuman and spatial conflicts at Sanjay Gandhi National Park, Mumbai. In A. Rademacher \& K. Sivaramakrishnan (Eds.), Cities, towns, and the places of nature (pp. 67-85). Hong Kong: Hong Kong University Press.

Latour, B. (1993). We have never been modern. Cambridge: Harvard University Press.

Mackenzie, J. M. (1988). The empire of nature: Hunting, conservation and british imperialism. Manchester: Manchester University Press.

Matheka, R. (2005). Antecedents to the community wildlife conservation programme in Kenya, 1946-1964. Environment and History, 11, 239-267.

Mawdsley, E., Mehra, D., \& Beazley, K. (2009). Nature lovers, picnickers and bourgeois environmentalism. Economic and Political Weekly, 44(11), 49-59.

Midgley, M. (1979). Beast and man: The roots of human nature. London; New York: Routledge.

Neumann, R. P. (2004). Moral and discursive geographies in the war for biodiversity in Africa. Political Geography, 23(7), 813-837.

Ogutu, J. O., Owen-Smith, N., Piepho, H.-P., Said, M. Y., Kifugo, S. C., Reid, R. S., et al. (2013). Changing wildlife populations in Nairobi National Park and adjoining Athi-Kaputiei Plains: Collapse of the migratory wildebeest. The Open Conservation Biology Journal, 7, 11-26.

Osano, P. M., Said, M. Y., de Leeuw, J., Ndiwa, N., Kaelo, D., Schomers, S., et al. (2013). Why keep lions instead of livestock? Assessing wildlife tourism-based payment for ecosystem services involving herders in the Maasai Mara. Kenya. Natural Resources Forum, 37(4), 242 256. 
Robbins, P. (2001). Tracking invasive land covers in India, or why our landscapes have never been modern. Annals of the Association of American Geographers, 91(4), 637-659.

Rodary, E. (2009). Mobilizing for nature in southern African community-based conservation policies, or the death of the local. Biodiversity and Conservation, 18(10), 2585-2600.

Rodary, E. (2016). Politiques de connectivité. Conservation de la nature et fin de la modernité en Afrique australe. Habilitation à Diriger des Recherches, University of Grenoble.

Rodriguez, L. C., Henson, D., Herrero, M., Nkedianye, D., \& Reid, R. (2012). Private farmers' compensation and viability of protected areas: the case of Nairobi National Park and Kitengela dispersal corridor. International Journal of Sustainable Development and World Ecology, 19 (1), 34-43.

Scott, J. C. (1985). Weapons of the weak: Everyday forms of peasant resistance. New Haven: Yale University Press.

Sekar, N. (2013). Tolerance for the charismatic marauders: Culture in wildlife conservation. Economic and Political Weekly June 15: 10-13.

Surve, N. (2015). Ecology of leopard in Sanjay Gandhi National Park, Maharashtra with special reference to its abundance, prey selection and food habit. Mumbai: Wildlife Institute of India; Maharashtra Forest Department, SGNP.

Tiwari, K. (2008). City Forest Report 2006-07. Mumbai: BNHS.

Tiwari, K. (2009). Preliminary study on the diet composition of the leopard in Sanjay Gandhi National Park. Mumbai: BNHS.

Toth, A. B., Lyons, S. K., \& Behrensmeyer, A. K. (2014). A century of change in Kenya's mammal communities: increased richness and decreased uniqueness in six protected areas. PLOS ONE, 9(4), e93092.

Western, D., Russell, S., \& Cuthill, I. (2009). The status of wildlife in protected areas compared to non-protected areas of Kenya. PLOS ONE, 4(7), e6140.

Wolch, J. (1998). Zoopolis. In J. Wolch \& J. Emel (Eds.), Animal geographies; place, politics and identity in the nature-culture borderlands (pp. 381-404). New York: Verso.

Wolch, J., \& Emel, J. (Eds.). (1998). Animal geographies; place, politics and identity in the nature-culture borderlands. New York: Verso. 


\section{Author Query Form}

\section{Book ID：456116_1_En}

Chapter No: 7

\section{Springer}

the language of science

\section{Please ensure you fill out your response to the queries raised below and return this form along with your corrections.}

\section{Dear Author,}

During the process of typesetting your chapter, the following queries have arisen. Please check your typeset proof carefully against the queries listed below and mark the necessary changes either directly on the proof/online grid or in the 'Author's response' area provided below

\begin{tabular}{|c|c|c|}
\hline Query Refs. & Details Required & Author's Response \\
\hline AQ1 & $\begin{array}{l}\text { Please check and confirm if the authors and their respective affiliations have } \\
\text { been correctly identified. Amend if necessary. }\end{array}$ & \\
\hline AQ2 & Please check and confirm if the author names and initials are correct. & \\
\hline AQ3 & Please confirm if the section headings identified are correct. & \\
\hline AQ4 & $\begin{array}{l}\text { There is a closing quotation mark after "Mumbai but possessing "rural" } \\
\text { characteristics". Please clarify where the opening quotation mark should be } \\
\text { given. }\end{array}$ & \\
\hline AQ5 & Please provide the source for Fig. 2 if possible. & \\
\hline AQ6 & $\begin{array}{l}\text { References Edgaonkar and Chellam (1998), Desgroppes (2008), Athreya } \\
\text { (2011), Ghosal (2012), Guha and Martinez-Alier (1996) are cited in the text } \\
\text { but not provided in the reference list. Please provide the respective } \\
\text { references in the list or delete these citations. }\end{array}$ & \\
\hline AQ7 & $\begin{array}{l}\text { Kindly note that the reference Ogutu (2013), Toth et al. (2013) have been } \\
\text { changed to Ogutu et al. (2013), Toth et al. (2014) so that this citation } \\
\text { matches the list. }\end{array}$ & \\
\hline AQ8 & Please provide the appropriate citation instead of Chap. 20. & \\
\hline AQ9 & $\begin{array}{l}\text { Please check the sentence "... positioned on this "ladder of environmen- } \\
\text { talism", or bourgeois anti-environmentalists? ...". for clarity, and correct if } \\
\text { necessary. }\end{array}$ & \\
\hline AQ10 & $\begin{array}{l}\text { References Benhammou (2007), Galhano Alves (2002), Guha (1989), } \\
\text { Robbins (2001) are given in the list but not cited in the text. Please cite them } \\
\text { in text or delete them from the list. }\end{array}$ & \\
\hline
\end{tabular}

